\title{
Estimating how extra calories from alcohol consumption are likely an overlooked contributor to youth obesity
}

\section{Kate Battista, MMath; Scott T. Leatherdale, PhD}

This article has been peer reviewed.

\begin{abstract}
Introduction: Youth obesity rates in Canada continue to rise. In this study, we produced conservative estimates of the potential excess calories from alcohol use across different alcohol consumption patterns common among Canadian youth to assess whether alcohol use should be considered in future obesity prevention strategies.
\end{abstract}

Methods: Using data from 10144 Grade 12 students participating in the COMPASS study (2013/14), we estimated the number of calories consumed per year from alcohol consumption. Our estimates were based on three different generic types of alcoholic beverages, which were grouped according to average calorie content (vodka coolers; beer [5\%]; and beer [4\%], wine and liquor) across different frequencies of alcohol use and binge drinking.

Results: Results indicated high potential caloric intake for students who binge drank, as well as high variability in the estimates for calories consumed based on common consumption patterns for the different beverage types. For instance, $27.2 \%$ of students binge drank once per month, meaning they consumed between 6000 and 13200 calories in one year (equivalent to $0.78-1.71 \mathrm{~kg}$ of fat). For the $4.9 \%$ of students who binge drank twice per week, the total calories in one year would range from 52000 to 114400 (equivalent to $6.74-14.83 \mathrm{~kg}$ of fat).

Conclusion: Current recommendations for preventing youth obesity do not generally include any consideration of alcohol use. The high prevalence of frequent alcohol consumption and binge drinking by youth in this study and the substantial number of calories contained in alcoholic beverages suggest alcohol use among youth may warrant consideration in relation to youth obesity prevention.

Keywords: alcohol use, binge drinking, prevention strategies, weight gain, obesity, extra calories, energy intake, youth

\section{Introduction}

Excessive weight gain among youth is a public health problem, given the evidence that youth obesity is associated with a variety of immediate and long-term health effects including type 2 diabetes and heart disease. ${ }^{1}$ Data from the 2009 to 2011 Canadian Health Measures Survey suggest that among Canadian youth aged 12 to 17 years, $29.6 \%$ of boys and $30.5 \%$ of girls were overweight or obese. ${ }^{2}$ Considering that the prevalence of overweight and obesity among youth in Canada has increased dramatically in the past two decades, ${ }^{3}$ a variety of prevention strategies and solutions have been developed to help stem this growing problem. These include both population-level ${ }^{4,5}$ and clini$\mathrm{cal}^{6,7}$ approaches, generally focussed on achieving energy balance through increasing physical activity and improving diet.

In the domain of diet, the additional calories from sugar-sweetened beverage (SSB) consumption (e.g. fruit drinks or soft drinks) has recently received considerably more attention given their association with youth obesity. ${ }^{8}$ In fact, a 2016 report

\section{Highlights}

- Youth obesity is a public health concern. Current guidelines on obesity prevention focus on food and sugar-sweetened beverage consumption, but may overlook the potential impact of calories from alcoholic beverages.

- Frequent and heavy alcohol use is common among youth in Canada. Calories from alcohol lack nutritional value and tend to be additive to the diet.

- This study provides conservative estimates of calories consumed from alcohol based on observed drinking patterns among Grade 12 youth in Ontario and Alberta.

- A high prevalence of frequent alcohol consumption and binge drinking by youth corresponds to a substantial number of calories consumed over a one-year period.

by the Canadian Standing Senate Committee on Social Affairs, Science and Technology, Obesity in Canada: A Wholeof-Society Approach for a Healthier Canada, recommends the federal government consider a tax on SSBs. ${ }^{9}$ However, while stakeholders work to develop strategies to stem SSB consumption in youth populations, little attention has been given to the potential impact of excess calories from alcoholic beverage consumption. Some evidence does exist highlighting an association between alcohol consumption and weight gain or obesity risk among youth, ${ }^{10-13}$ especially among females. ${ }^{12-13}$ Not only can alcohol represent a potentially significant source of calories $(7.1 \mathrm{kcal} / \mathrm{g})$ with limited to no nutritional value, but alcohol tends to be additive to caloric intake. ${ }^{14-15}$ Alcohol 
intake can also act as an indirect risk factor for obesity through modified diet, such as increased food intake after alcohol consumption $^{15}$ and associations with disordered eating such as binge eating. ${ }^{16}$

The discussion around alcohol use and weight gain has generally been focussed on adult populations, and in fact little research is available on the link between alcohol use and weight gain or obesity in youth. High rates of frequent and heavy alcohol use are common among Canadian youth, with one 2011 study finding $25.5 \%$ of Grade 9 to Grade 12 students were considered current binge drinkers. ${ }^{17}$ In addition, there is evidence that younger age of peak alcohol consumption is associated with both heavier drinking and obesity into adulthood. ${ }^{18}$ Youth should therefore be considered a potential at-risk population when considering this link.

The COMPASS (Cohort Study of Obesity, Marijuana Use, Physical Activity, Alcohol Use, Smoking and Sedentary Behaviours) host study is a cohort study of secondary school students in Ontario and Alberta with the aim of measuring the impact of policy decisions on student health behaviours. ${ }^{19}$ As part of this study, an annual student survey includes measures of drinking and binge drinking frequencies. Our study uses secondary data from the COMPASS study to produce conservative estimates of the potential total calories from alcohol use across different alcohol consumption patterns common among youth within the study. Considering there is ample literature discussing the problems associated with binge drinking during adolescence, the focus of this paper is not to make additional claims on the health risks of drinking, but rather to highlight the potential issue of additional calorie intake from alcohol consumption.

\section{Methods}

\section{Design}

This study uses secondary cross-sectional data from Year $2(2013 / 14)$ of the COMPASS host study. ${ }^{19}$ Year 2 data were used because the first year of study consisted of a smaller sample of schools, and as such Year 2 comprised a larger sample of Grade 12 students. The data were collected using the COMPASS Student Questionnaire and active-information passive-consent procedures. All procedures were approved by the University of
Waterloo's Office of Research Ethics and participating school boards. A full description of the study methods is available in print $^{19}$ or online (www.compass.uwaterloo .ca).

\section{Measurements}

This study is based on secondary data obtained from the student questionnaire. The COMPASS student-level questionnaire collects individual student data pertaining to multiple behavioural domains (e.g. alcohol use, tobacco use, obesity, physical activity, eating behaviour, etc.), correlates of these behaviours and demographic characteristics. In each school, the questionnaire was used to collect whole-school samples during class time. The questionnaire items were based on national standards or current national public health guidelines as described elsewhere. ${ }^{19}$

\section{Participants}

In Year 2, 89 schools in Ontario $(\mathrm{n}=79)$ and Alberta ( $\mathrm{n}=10)$ that approved the use of active-information passive-consent parental permission protocols were recruited to participate in COMPASS. Students could decline to participate at any time. The overall completion rate was $78.2 \%$ of enrolled students; the primary reason for nonparticipation was absenteeism at the time of the data collection. For the purpose of this paper, we used the Year 2 data from 10144 students (4927 females,
5217 males) in Grade 12; previous research has demonstrated that the Grade 12 respondents (typically aged 16 to 18 years) have the highest rates of alcohol use. ${ }^{17}$ Consistent with COMPASS data collection protocols, these students completed the COMPASS student questionnaire in class time on the day of their schools' scheduled data collection.

\section{Measures}

The two alcohol-consumption questions (on drinking frequency and binge drinking frequency) on the questionnaire are taken from existing national surveillance tools for youth populations in Canada. ${ }^{20}$ The questionnaire defined one drink as "1 regular sized bottle, can or draft of beer, 1 glass of wine; 1 bottle of cooler; 1 shot of liquor; or 1 mixed drink" consistent with the standard serving sizes defined by the Canadian Centre on Substance Abuse (CCSA). ${ }^{21}$

\section{Frequency of alcohol use}

Drinking frequency was assessed by asking the question "In the last 12 months, how often did you have a drink of alcohol that was more than just a sip?" The response options were: "I have never drunk alcohol"; "I did not have a drink of alcohol in the last 12 months"; "I have only had a sip of alcohol"; "Less than once a month"; "Once a month”; "2 or 3 times a month"; “Once a week”; "2 or 3 times a

\section{TABLE 1}

Drinking and binge drinking frequencies by sex among Grade 12 students in Year $2(2013 / 14)$ of the COMPASS Study, Ontario and Alberta, Canada

\begin{tabular}{|c|c|c|c|c|c|c|}
\hline & \multicolumn{2}{|c|}{ Total } & \multicolumn{2}{|c|}{ Males } & \multicolumn{2}{|c|}{ Females } \\
\hline & (n) & $\%$ & (n) & $\%$ & (n) & $\%$ \\
\hline \multicolumn{7}{|l|}{ Drinking } \\
\hline Did not drink & 2408 & 24.3 & 1222 & 24.1 & 1186 & 24.4 \\
\hline Less than once per month & 2193 & 22.2 & 932 & 18.5 & 1261 & 25.9 \\
\hline 1-3 times per month & 3467 & 34.9 & 1704 & 33.6 & 1763 & 36.2 \\
\hline $1-3$ times per week & 1564 & 15.7 & 973 & 19.2 & 591 & 12.1 \\
\hline $4+$ times per week & 301 & 3.0 & 235 & 4.6 & 66 & 1.4 \\
\hline Total & 9933 & $100.1^{\mathrm{a}}$ & 5066 & 100.0 & 4867 & 100.0 \\
\hline \multicolumn{7}{|l|}{ Binge drinking } \\
\hline Did not binge drink & 3900 & 39.2 & 1860 & 36.7 & 2040 & 41.9 \\
\hline Less than once per month & 2205 & 22.2 & 1020 & 20.1 & 1185 & 24.4 \\
\hline $1-3$ times per month & 2699 & 27.2 & 1412 & 27.8 & 1287 & 26.5 \\
\hline 1 time per week & 649 & 6.5 & 421 & 8.3 & 228 & 4.7 \\
\hline $2+$ times per week & 484 & 4.9 & 360 & 7.1 & 124 & 2.5 \\
\hline Total & 9937 & 100.0 & 5073 & 100.0 & 4864 & 100.0 \\
\hline
\end{tabular}

${ }^{\mathrm{a}}$ Total does not add up to 100.0 due to rounding. 
week"; "4 to 6 times a week"; and "Every day." Response categories were combined to create five different frequencies of alcohol use: "Did not drink"; "Less than once per month"; "1 to 3 times per month"; "1 to 3 times per week"; and " 4 or more times per week." The response rate for this question was $97.92 \%$; students who did not respond to the question were excluded from the analyses.

\section{Frequency of binge drinking}

The binge drinking frequency measure provides additional insight into consumption levels by establishing a minimum threshold of five drinks per occasion. Respondents were asked "In the last 12 months, how often did you have 5 drinks of alcohol or more on one occasion?" The response options were "I have never done this"; "I did not have 5 or more drinks on one occasion in the last 12 months"; "Less than once a month"; "Once a month"; "2 to 3 times a month"; "Once a week"; and " 2 to 5 times a week", or "Daily or almost daily." Response categories were combined to create five different frequencies of binge drinking: "Did not binge drink"; "Less than once per month"; "1 to 3 times per month"; "1 time per week"; and " 2 or more times per week." The response rate for this question was $97.96 \%$; students who did not respond to the question were excluded from the analyses. While the available questionnaire measure for binge drinking does not align with the low-risk drinking guideline for binge drinking among females (four or more drinks on one occasion), ${ }^{21}$ the questionnaire measure is consistent with national youth surveillance measures ${ }^{20}$ and provides a more conservative estimate of binge drinking among females.

\section{Analyses}

We calculated drinking and binge drinking frequencies by sex, and used chisquare tests to examine differences in drinking patterns by sex. We obtained the calorie content of various types of alcohol from Health Canada's Canadian Nutrient File $(\mathrm{CNF})^{22}$ and scaled for standard drink sizes using standard drink definitions from the CCSA. ${ }^{21}$ The CNF database identifies 12 alcoholic beverages and corresponding calorie counts. We scaled calorie counts to standard drink sizes using the CCSA definitions: one serving is equal to one bottle of beer or cooler (341 ml [12 oz.]), one shot of liquor (43 ml [1.5 oz.]), or one glass of wine (142 $\mathrm{ml}$ [5 oz.]). Using the CNF list, we grouped drinks by approximate number of calories per standard serving to identify three representative drink classes of high, medium and low calorie content. Vodka coolers have a high calorie content, at 220 calories per standard serving. Regular beer (5\% alcohol by volume) has a moderate calorie content, at 140 calories per standard serving. Light beer ( $4 \%$ alcohol by volume), table wines (red and white) and liquor shots (including gin, rum, vodka and whiskey) all contain approximately 100 calories per standard serving. We estimated the number of calories students consumed from alcohol for different generic types of alcoholic beverages according to average calorie content [vodka cooler; beer ( $5 \%)$; and beer $(4 \%)$, wine and liquor], and for the five categories each for frequency of alcohol use and frequency of binge drinking. We converted the estimated total calories consumed over a one-year period to equivalent kilograms using the formula 7716 calories equal one kilogram. ${ }^{23}$ We used SAS version 9.4 (SAS Institute Inc., Cary, NC,
USA) for all statistical analyses. A significance level of $p<.05$ was used in all statistical tests.

\section{Results}

Drinking and binge drinking frequencies among the students in Year 2 are presented by sex in Table 1. Overall, 53.6\% of students reported drinking alcohol at least once per month, while $18.7 \%$ reported drinking at least once per week. Although the prevalence of nondrinking was similar among males and females ( $24.1 \%$ and $24.4 \%$ respectively, $p=.774$ ), chi-square $\left(\chi^{2}\right)$ tests showed significantly different drinking patterns by sex $\left(\chi^{2}=235.19\right.$, degrees of freedom $[\mathrm{df}]=4$, $p<.001$ ), with males drinking more frequently than females. Overall, $38.6 \%$ of students reported binge drinking at least once per month, while $11.4 \%$ reported binge drinking at least once per week. Chi-square tests showed significantly different binge drinking patterns by sex $\left(\chi^{2}=194.60\right.$, df $\left.=4, p<.001\right)$, with males binge drinking more frequently

TABLE 2

Additional calories students consumed by drinking and binge drinking over a one-year period, by beverage type and consumption frequency among Grade 12 students in Year $2(2013 / 14)$ of the COMPASS Study, Ontario and Alberta, Canada

\begin{tabular}{|c|c|c|c|c|}
\hline & $\begin{array}{c}\% \text { of } \\
\text { students }\end{array}$ & Beverage type & $\begin{array}{c}\text { Calories } \\
\text { consumed }\end{array}$ & $\begin{array}{c}\text { Equivalent kilograms } \\
\text { of fat from alcohol } \\
\text { calories }\end{array}$ \\
\hline \multicolumn{5}{|l|}{ Drinking frequency } \\
\hline Once per month & 34.9 & $\begin{array}{l}\text { Vodka cooler } \\
\text { Beer }(5 \%) \\
\text { Beer }(4 \%) \text {, wine, liquor }\end{array}$ & $\begin{array}{l}2640 \\
1680 \\
1200\end{array}$ & $\begin{array}{l}0.34 \\
0.22 \\
0.16\end{array}$ \\
\hline Once per week & 15.7 & $\begin{array}{l}\text { Vodka cooler } \\
\text { Beer }(5 \%) \\
\text { Beer }(4 \%) \text {, wine, liquor }\end{array}$ & $\begin{array}{r}11440 \\
7280 \\
5200\end{array}$ & $\begin{array}{l}1.48 \\
0.94 \\
0.67\end{array}$ \\
\hline Four times per week & 3.0 & $\begin{array}{l}\text { Vodka cooler } \\
\text { Beer }(5 \%) \\
\text { Beer }(4 \%) \text {, wine, liquor }\end{array}$ & $\begin{array}{l}45760 \\
29120 \\
20800\end{array}$ & $\begin{array}{l}5.93 \\
3.77 \\
2.70\end{array}$ \\
\hline Binge drinking freq & ncy & & & \\
\hline Once per month & 27.2 & $\begin{array}{l}\text { Vodka cooler } \\
\text { Beer }(5 \%) \\
\text { Beer }(4 \%) \text {, wine, liquor }\end{array}$ & $\begin{array}{r}13200 \\
8400 \\
6000\end{array}$ & $\begin{array}{l}1.71 \\
1.09 \\
0.78\end{array}$ \\
\hline Once per week & 6.5 & $\begin{array}{l}\text { Vodka cooler } \\
\text { Beer }(5 \%) \\
\text { Beer }(4 \%) \text {, wine, liquor }\end{array}$ & $\begin{array}{l}57200 \\
36400 \\
26000\end{array}$ & $\begin{array}{l}7.41 \\
4.72 \\
3.37\end{array}$ \\
\hline Twice per week & 4.9 & $\begin{array}{l}\text { Vodka cooler } \\
\text { Beer }(5 \%) \\
\text { Beer }(4 \%) \text {, wine, liquor }\end{array}$ & $\begin{array}{r}114400 \\
72800 \\
52000\end{array}$ & $\begin{array}{r}14.83 \\
9.43 \\
6.74\end{array}$ \\
\hline
\end{tabular}


than females. Males were more than twice as likely as females to binge drink at least once per week $(15.4 \%$ and $7.2 \%$, respectively), and nearly three times as likely as females to binge drink two or more times per week ( $7.1 \%$ and $2.5 \%$, respectively).

\section{Calorie consumption estimates}

Table 2 presents estimates for the total calories consumed over a one-year period by students who reported drinking at least once a month, by alcohol consumption frequency and beverage type. The results show high variability in the total calories consumed across the different beverage types and consumption frequencies. For instance, among the $15.7 \%$ of students who drank once per week, if we assume they only consumed one drink per occasion, they would have consumed between 5200 and 11440 calories in one year (equivalent to $0.67-1.48 \mathrm{~kg}$ of fat). Among the $3.0 \%$ of students $(4.6 \%$ of males, $1.4 \%$ of females) who drank four times per week, the total calories in one year would range from 20800 to 45760 (equivalent to 2.70 - $5.93 \mathrm{~kg}$ of fat). Figure 1 shows the calorie estimates, assuming one drink per occasion by beverage type and the percentage of students who fall into each estimation range.

Among the $27.2 \%$ of students who binge drank once per month, if we assume they only consumed five drinks per binge drinking occasion, they would have consumed between 6000 and 13200 calories in a one-year period (equivalent to 0.78 $1.71 \mathrm{~kg}$ of fat; Table 2). Among the $4.9 \%$ of students $(7.1 \%$ of males, $2.5 \%$ of females) who binge drank twice per week, the total calories in one year would range from 52000 to 114400 (equivalent to 6.74 $14.83 \mathrm{~kg}$ of fat). Figure 2 shows the calorie estimates assuming five drinks per binge drinking occasion, by beverage type, and the percentage of students who fall into each estimation range.

\section{Discussion}

Youth obesity is a complex public health issue, particularly since obesity in adolescence can lead to adverse health consequences in adulthood. ${ }^{24}$ Obesity risk in youth is influenced by a variety of factors, including individual lifestyle factors such as food intake and physical activity. ${ }^{6,11}$ While alcohol use is only one component of the issue, modifiable risk factors are often interrelated, ${ }^{25}$ and these interrelationships should be recognized when developing public health interventions. ${ }^{26}$ Current recommendations for preventing youth obesity do not generally include any considerations

pertaining to alcohol use. ${ }^{4-7,9}$ For instance, even in the recent Senate report on obesity in Canada, ${ }^{9}$ none of the 21 prevention recommendations designed to address

FIGURE 1

Projections for additional calories consumed by students for one drink per occasion over a one-year period, by beverage type among Grade 12 students in Year $2(2013 / 14)$ of the COMPASS Study, Ontario and Alberta, Canada
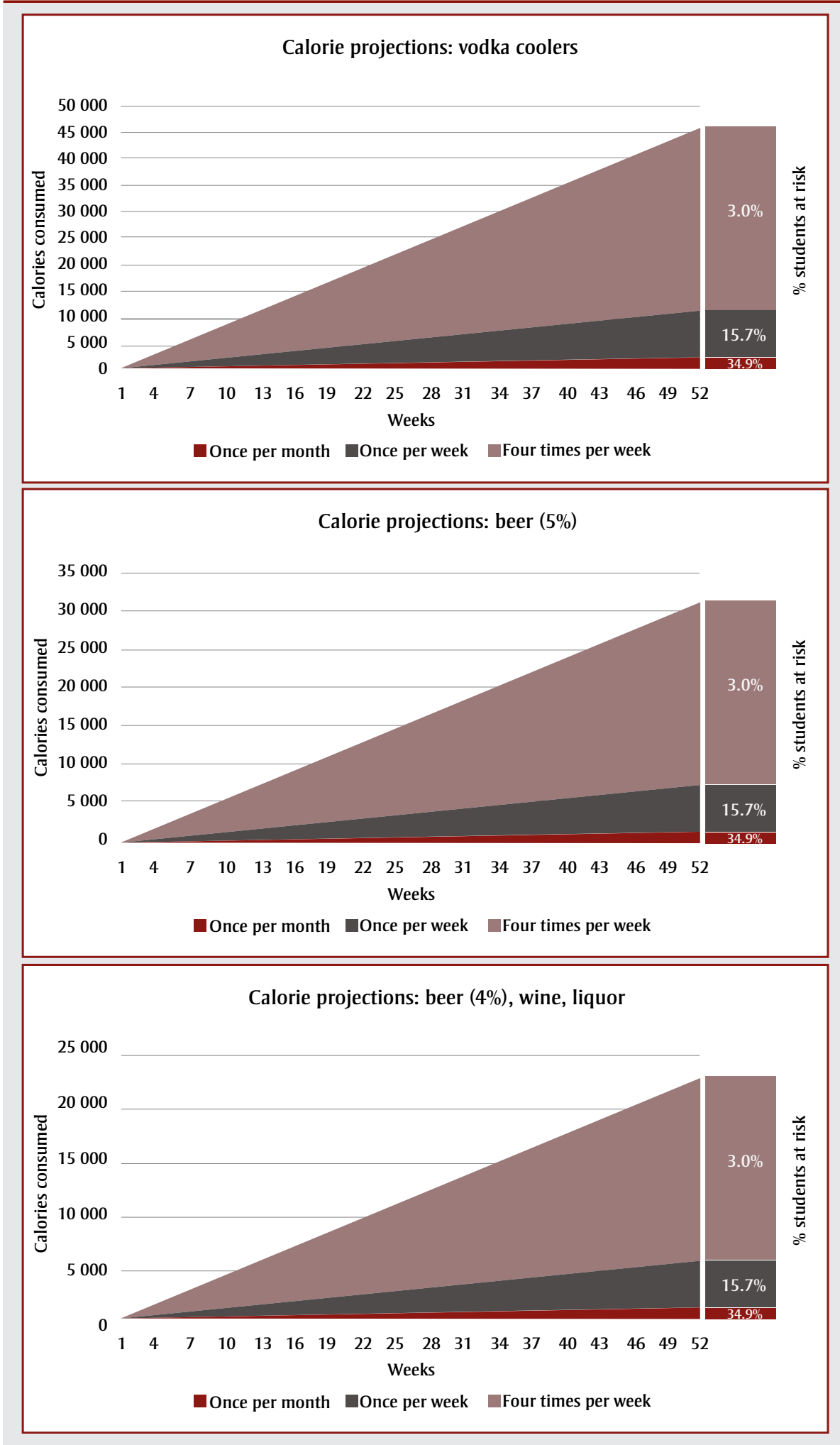
youth obesity in Canada mentioned or considered the potential role of alcohol use. In our study, the majority of youth in our sample reported consuming alcohol and

\section{FIGURE 2}

Projections for additional calories consumed for five drinks per occasion over a one-year period by beverage type, among Grade 12 students in Year $2(2013 / 14)$ of the COMPASS Study, Ontario and Alberta, Canada

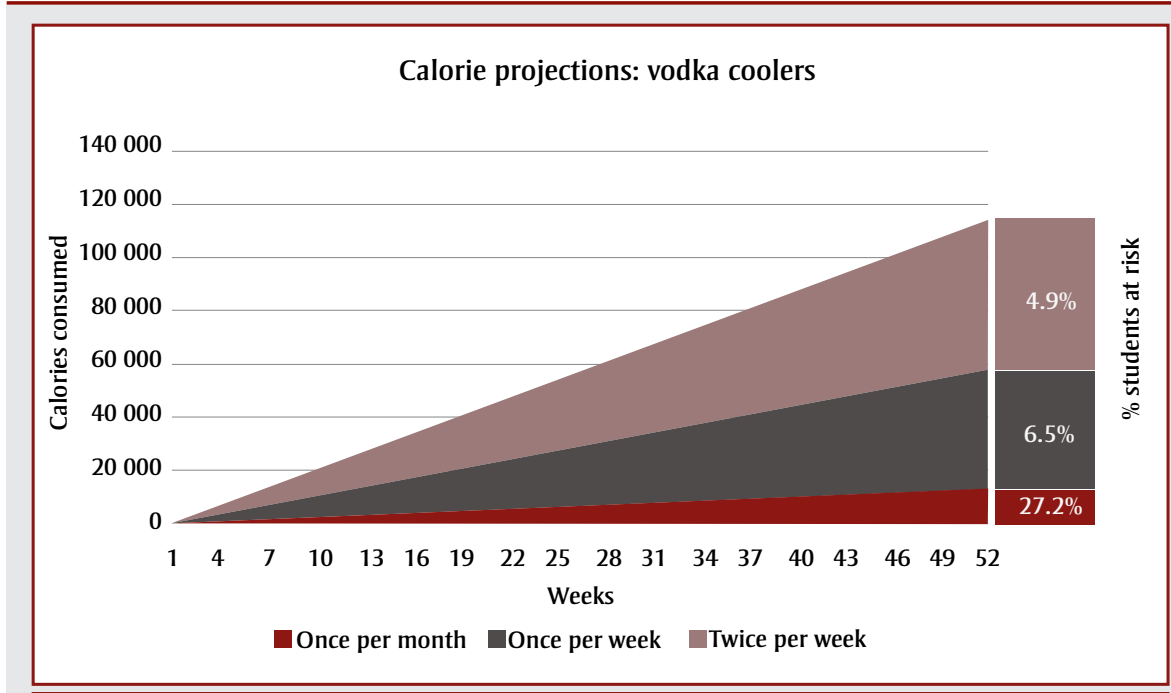

Calorie projections: beer (5\%)

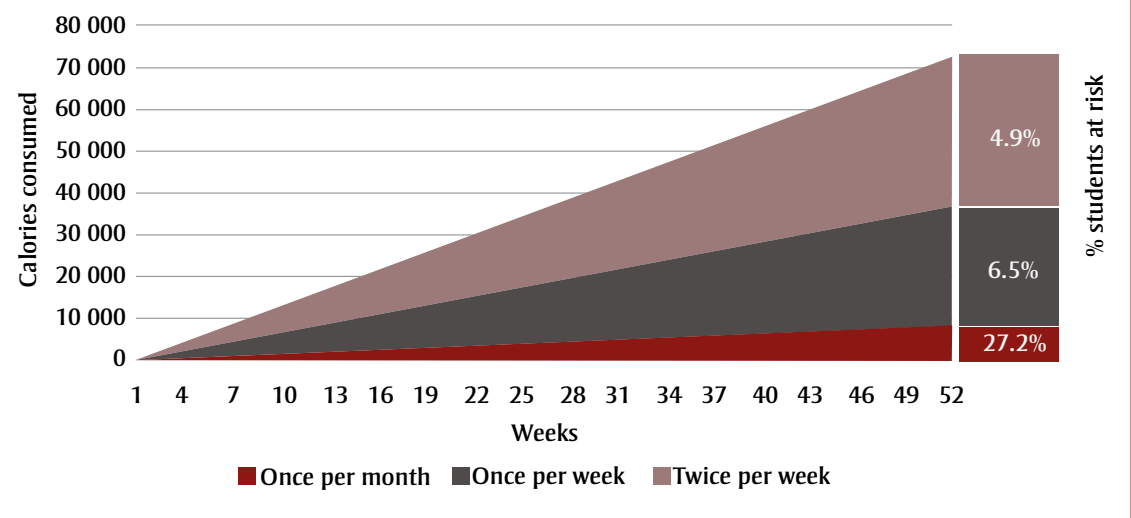

Calorie projections: beer (4\%), wine, liquor

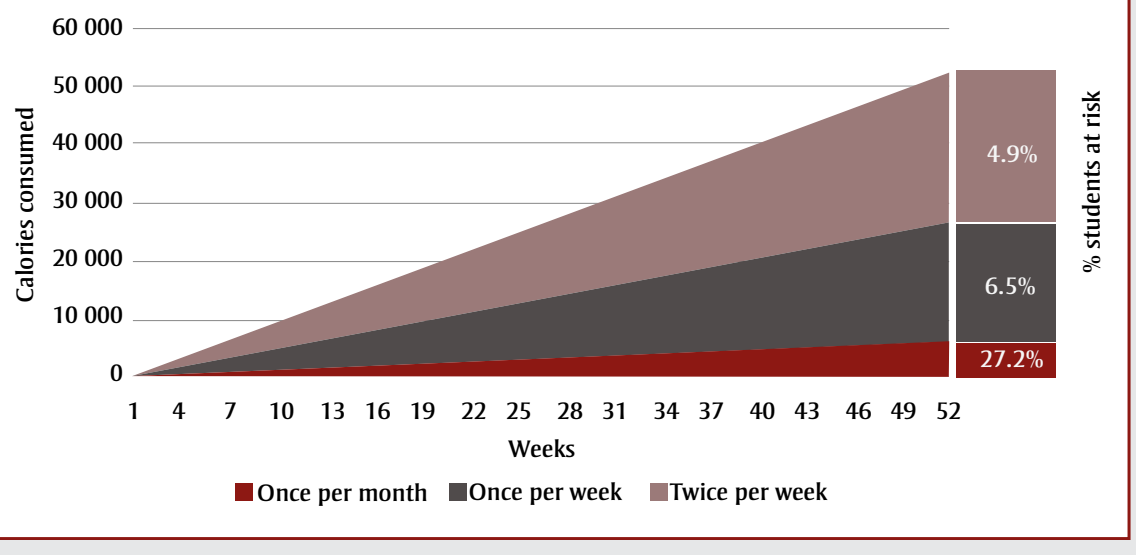
very conservative estimates of the potential calories consumed per drinking occasion based on estimates of students consuming either one drink or five drinks per drinking occasion from a large sample of Canadian youth. However, data from the 2015 Ontario Student Drug Use and Health Survey (OSDUHS) suggests that youth drinkers typically report drinking two or more drinks per drinking occasion rather than one. ${ }^{27}$ There is also emerging evidence to suggest that youth binge drinking episodes often involve 10 to 15 drinks per occasion rather than five. ${ }^{28}$ Despite the fact that we are presenting very conservative estimates, our projections for total calories consumed from alcohol are still quite high across a variety of drinking patterns that are common among Canadian youth. ${ }^{17,29}$

These data are subject to limitations. While the type of drink can be an important factor in total estimated calories, no information was available on the type of drinks typically consumed by students in the sample. Calorie information on mixed drinks was not included in the analysis, given the variability in types of mixes and proportions, so our estimates did not include the additional calories that would also be consumed from the added mix (i.e. soft drinks or juice). Many common cocktails can contain up to 490 calories per drink, ${ }^{30}$ which further suggests that our estimates are very conservative. The estimates given were also based on standard drink sizes. There is the potential for underestimation of total calories consumed if drinks are made larger than the standard size. For example, one pint of regular beer may be viewed as a single drink by respondents despite being the equivalent of 1.66 standard drinks. Additional information on the types of drinks commonly consumed would allow for more accurate estimation of calorie intake. 
These results are based on a secondary data analysis from a sample that is not nationally representative. Thus, the drinking patterns identified here may not be representative of all Canadian youth. Furthermore, due to the secondary nature of the analysis, the available measures to assess drinking and binge drinking frequency do not allow for specific measurements of alcohol intake. Additional information is needed on the number of drinks typically consumed per occasion, along with more exact frequencies of the number of drinking and binge drinking occasions.

There are numerous health risks associated with binge drinking during adolescence. ${ }^{31}$ While this study focussed on the potential additional caloric intake from alcohol consumption, there are many other negative immediate and long-term consequences of underage drinking that warrant consideration in public health interventions and education initiatives.

\section{Conclusion}

Despite the limitations discussed, this analysis has highlighted the need for researchers and stakeholders to consider alcohol more closely as a modifiable risk factor for overweight and obesity among youth. The high prevalence of frequent alcohol consumption and binge drinking by youth in this study, and the substantial number of calories contained in alcoholic beverages, suggest alcohol may be a key component of the obesity discussion that should not be overlooked.

\section{Acknowledgements}

The COMPASS study was supported by a bridge grant from the Canadian Institutes of Health Research (CIHR) Institute of Nutrition, Metabolism and Diabetes (INMD) through the "Obesity-Interventions to Prevent or Treat” priority funding awards (OOP-110788; grant awarded to S. T. Leatherdale) and an operating grant from the CIHR Institute of Population and Public Health (IPPH) (MOP-114875; grant awarded to S. T. Leatherdale). Dr. Leatherdale is a Chair in Applied Public Health funded by the Public Health Agency of Canada (PHAC) in partnership with the CIHR Institute of Neurosciences, Mental Health and Addiction (INMHA) and IPPH.

\section{Conflicts of interest}

The authors state that they have no competing interests in this work.

\section{Authors' contributions}

$\mathrm{KB}$ performed the analyses, interpreted the results, wrote the first draft of the introduction and methods, and worked on drafting sections of the discussion for this manuscript. SL conceived the manuscript idea, led the COMPASS host study, wrote sections of the discussion, and edited all portions of the manuscript.

\section{References}

1. US Department of Health and Human Services. The Surgeon General's vision for a healthy and fit nation. Rockville (MD): US Department of Health and Human Services, Office of the Surgeon General; 2010. 21 p.

2. Roberts KC, Shields M, de Groh M, et al. Overweight and obesity in children and adolescents: results from the 2009 to 2011 Canadian Health Measures Survey. Health Rep. 2012;23(3):37-41.

3. Tremblay $\mathbf{M}$, Shields $\mathrm{M}$, Laviolette $\mathrm{M}$, et al. Fitness of Canadian children and youth: results from the 20072009 Canadian Health Measures Survey. Health Rep. 2010;21 (1):7-20.

4. World Health Organization. Populationbased approaches to obesity prevention. Geneva (CH): World Health Organization Library, 2012. 54 p.

5. Ontario Agency for Health Protection and Promotion (Public Health Ontario). Addressing obesity in children and youth: evidence to guide action for Ontario. Toronto (ON): Queen's Printer for Ontario; 2013. 26 p.

6. Davis MM, Gance-Cleveland B, Hassink $\mathrm{S}$, et al. Recommendations for prevention of childhood obesity. Pediatrics. 2007;120(Suppl 4):S229-S253.

7. Peirson L, Fitzpatrick-Lewis D, Morrison $\mathrm{K}$, et al. Prevention of overweight and obesity in children and youth: a systematic review and meta-analysis. CMAJ Open. 2015;3(1):E23-33. doi: 10.9778/cmajo.20140053.

8. Malik V, Schulze M, Hu F. Intake of sugar-sweetened beverages and weight gain: a systematic review. Am J Clin Nutr. 2006;84(2):274-88.
9. Ogilvie KK, Eggleton A. Obesity in Canada: a whole-of-society approach for a healthier Canada. Report of the Standing Senate Committee on Social Affairs, Science and Technology. Ottawa (ON): Government of Canada; 2016. 56 p.

10. Berkey C, Rockett H, Colditz G. Weight gain in older adolescent females: the internet, sleep, coffee and alcohol. J Pediatr. 2008;153(5): 635-639.e1.

11. Croezen S, Visscher $\mathrm{T}$, ter Bogt, $\mathrm{N}$, Veling M, Haveman-Nies A. Skipping breakfast, alcohol consumption and physical inactivity as risk factors for overweight and obesity in adolescents: results of the E-MOVO project. Eur J Clin Nutr. 2009;63:405-12.

12. Farhat $\mathrm{T}$, Iannotti $\mathrm{R}$, Simons-Morton B. Overweight, obesity, youth and health-risk behaviors. Am J Prev Med. 2010;38(3):258-67.

13. Vagstrand K, Barkeling B, Forslund $H$ et al. Eating habits in relation to body fatness and gender in adolescentsresults from the 'SWEDES' study. Eur J Clin Nutr. 2007;61(4):517-25.

14. Suter P, Häsler E, Vetter W. Effects of alcohol on energy metabolism and body weight regulation: is alcohol a risk factor for obesity? Nutr Rev. 1997;55(5):157-71.

15. Yeomans M. Alcohol, appetite and energy balance: is alcohol intake a risk factor for obesity? Phys Behav. 2010;100(1):82-9.

16. Piran N, Robinson SR. Associations between disordered eating behaviours and licit and illicit substance use and abuse in a university sample. Addict Behav. 2006;31(10):1761-75.

17. Leatherdale ST, Rynard V. A cross-sectional examination of modifiable risk factors for chronic disease among a nationally representative sample of youth: are Canadian students graduating high school with a failing grade for health? BMC Public Health [Internet]. 2013 [cited 2016 Feb 27]; 13:569. Available from: http://dx.doi .org/10.1186/1471-2458-13-569

18. Fan AZ, Russell M, Stranges S, Dorn J, Trevisan, M. Association of lifetime alcohol drinking trajectories with cardiometabolic risk. J Clin Endocrinol Metab. 2008;93(1):154-61. 
19. Leatherdale ST, Brown KS, Carson V, et al. The COMPASS study: a longitudinal hierarchical research platform for evaluating natural experiments related to changes in school-level programs, policies and built environment resources. BMC Public Health [Internet]. 2014 [cited 2016 Feb 27];14:331. Available from: http://dx.doi.org/10 .1186/1471-2458-14-331

20. Elton-Marshall T, Leatherdale ST, Manske SR, Wong K, Ahmed R, Burkhalter R. Research methods of the Youth Smoking Survey (YSS). Chronic Dis Inj Can. 2011;32(1): 47-54.

21. Canadian Centre on Substance Abuse. Low risk drinking guide summary: youth and alcohol [Internet]. National Alcohol Strategy Advisory Committee. Ottawa (ON): Canadian Centre on Substance Abuse; 2014. Available from: http://www.ccsa.ca/Resource $\%$ 20Library/CCSA-Youth-and-Alcohol -Summary-2014-en.pdf

22. Canadian Nutrient File (CNF) database [Internet]. Ottawa (ON): Health Canada; 2015. Available from: http:// www.hc-sc.gc.ca/fn-an/nutrition /fiche-nutri-data/cnf_downloads -telechargement_fcen-eng.php

23. Centers for Disease Control and Prevention. Healthy weight: finding a balance [Internet]. Atlanta (GA): Centers for Disease Control and Prevention; 2015. Available at: https://www.cdc .gov/healthyweight/calories/

24. Must A, Strauss RS. Risks and consequences of childhood and adolescent obesity. Int $\mathrm{J}$ Obes Relat Metab Disord. 1999;23(Suppl 2):S2-S11.

25. deRuiter W, Cairney J, Leatherdale S, Faulkner G. A longitudinal examination of the interrelationship of multiple health behaviours. Am J Prev Med. 2014;47(3):283-9.

26. deRuiter W, Cairney J, Leatherdale S, Faulkner G. The period prevalence of risk behaviour co-occurrence among Canadians. Prev Med. 2016;85:11-6.

27. Boak A, Hamilton HA, Adlaf EM, Mann RE. Drug use among Ontario students, 1977-2015: detailed OSDUHS findings (CAMH Research Document Series No. 41). Toronto (ON): Centre for Addiction and Mental Health; 2015. 52 p.
28. Patrick ME. A call for research on high-intensity alcohol use. Alcohol Clin Exp Res. 2016;40:256-9.

29. Herciu AC, Laxer RE, Cole A, Leatherdale ST. A cross-sectional study examining factors associated with youth binge drinking in the COMPASS study: Year 1 data. J Alcohol Drug Depend [Internet]. 2014;2:172. Available from: http://dx .doi.org/10.4172/2329-6488.1000172

30. National Institute on Alcohol Abuse and Alcoholism (NIAAA). Alcohol calorie calculator [Internet]. Bethesda (MD): NIAAA [date unknown; cited 2016 Mar 01]. Available from: http:// rethinkingdrinking.niaaa.nih.gov / Tools / Calculators / Calorie -Calculator.aspx

31. Miller J, Naimi T, Brewer R, Everett Jones S. Binge drinking and associated health risk behaviors among high school students. Pediatrics. 2007; 119(1):76-85. 